\title{
Patient-reported dyspnea and health predict waitlist mortality in patients waiting for lung transplantation in Japan
}

\author{
Masaki Ikeda', Toru Oga²*, Toyofumi F. Chen-Yoshikawa3, Junko Tokuno' , Takahiro Oto ${ }^{4}$, Tomoyo Okawa ${ }^{4}$, \\ Yoshinori Okada ${ }^{5}$, Miki Akiba ${ }^{6}$, Satona Tanaka ${ }^{1}$, Yoshito Yamada ${ }^{1}$, Yojiro Yutaka ${ }^{1}$, Akihiro Ohsumi ${ }^{1}$, \\ Daisuke Nakajima', Masatsugu Hamaji ${ }^{1}$, Maki Isomi ${ }^{1}$, Kazuo Chin ${ }^{7}$ and Hiroshi Date ${ }^{1}$
}

\begin{abstract}
Background: Waitlist mortality due to donor shortage for lung transplantation is a serious problem worldwide. Currently, the selection of recipients in Japan is mainly based on the registration order. Hence, scientific evidence for risk stratification regarding waitlist mortality is urgently needed. We hypothesized that patient-reported dyspnea and health would predict mortality in patients waitlisted for lung transplantation.

Methods: We analyzed factors related to waitlist mortality using data of 203 patients who were registered as candidates for lung transplantation from deceased donors. Dyspnea was evaluated using the modified Medical Research Council (mMRC) dyspnea scale, and the health status was determined with St. George's Respiratory Questionnaire (SGRQ).
\end{abstract}

Results: Among 197 patients who met the inclusion criteria, the main underlying disease was interstitial lung disease (99 patients). During the median follow-up period of 572 days, 72 patients died and 96 received lung transplantation (69 from deceased donors). Univariable competing risk analyses revealed that both mMRC dyspnea and SGRQ Total score were significantly associated with waitlist mortality $(p=0.003$ and $p<0.001$, respectively) as well as age, interstitial lung disease, arterial partial pressure of carbon dioxide, and forced vital capacity. Multivariable competing risk analyses revealed that the MMRC and SGRQ score were associated with waitlist mortality in addition to age and interstitial lung disease.

Conclusions: Both mMRC dyspnea and SGRQ score were significantly associated with waitlist mortality, in addition to other clinical variables such as patients' background, underlying disease, and pulmonary function. Patient-reported dyspnea and health may be measured through multi-dimensional analysis (including subjective perceptions) and for risk stratification regarding waitlist mortality.

Keywords: Lung transplantation, Waitlist mortality, Health-related quality of life, Modified Medical Research Council dyspnea scale, St. George's Respiratory Questionnaire

*Correspondence: ogato@med.kawasaki-m.ac.jp

2 Department of Respiratory Medicine, Kawasaki Medical School, 577, Matsushima, Kurashiki, Okayama 701-0192, Japan

Full list of author information is available at the end of the article

\section{Background}

Lung transplantation has been recognized as an effective treatment for patients with various end-stage pulmonary diseases; however, shortage of lung donors is a major challenge worldwide. Due to the imbalance between demand for donor organs and supply, waitlist mortality original author(s) and the source, provide a link to the Creative Commons licence, and indicate if changes were made. The images or other third party material in this article are included in the article's Creative Commons licence, unless indicated otherwise in a credit line to the material. If material is not included in the article's Creative Commons licence and your intended use is not permitted by statutory regulation or exceeds the permitted use, you will need to obtain permission directly from the copyright holder. To view a copy of this licence, visit http://creativecommons.org/licenses/by/4.0/. The Creative Commons Public Domain Dedication waiver (http://creativeco mmons.org/publicdomain/zero/1.0/) applies to the data made available in this article, unless otherwise stated in a credit line to the data. 
remains high [1]. In Japan, the average waiting time for transplantation is $>800$ days, resulting in a considerable number of deaths while on the waitlist [2]. Therefore, measures to reduce waitlist mortality are urgently warranted. For this purpose, appropriate risk stratification of patients waitlisted for lung transplantation is necessary.

In the U.S., the lung allocation score (LAS) system was implemented in 2005 to reduce the waitlist time and mortality, as well as to improve the likelihood of 1-year post-transplantation survival [3]. The LAS system has been adopted by Eurotransplant [4] and will be possibly introduced in various countries including Japan. This system is primarily based on multi-dimensional analyses; it is weighted based on underlying diseases and calculated mostly through physiological measures [5].

Dyspnea and health-related quality of life (HRQL) are the main targets for improvement after lung transplantation, in addition to survival. Nevertheless, the ranking of these subjective measures in the assessment of patients waitlisted for lung transplantation remains unclear. These patient-reported measures are not included in the factors contributing to the LAS; also, the LAS does not reflect them [6]. This indicates that they should be assessed separately from the LAS.

Assessment of dyspnea and HRQL using questionnaires in patients with respiratory diseases is mainly based on preceding experience and information obtained from studies of chronic airway diseases, such as asthma and chronic obstructive pulmonary disease (COPD). Dyspnea is the main symptom in these patients and a major contributor to poor health. Assessment of dyspnea [7] and health status [8] provides useful prognostic information regarding mortality in patients with COPD, thereby contributing to the development of subsequent multi-dimensional analysis not solely based on pulmonary function $[9,10]$.

Therefore, we hypothesized that patient-reported dyspnea and HRQL would predict waitlist mortality in patients waitlisted for lung transplantation in Japan, even though their underlying diseases are heterogeneous. This may provide useful information for better stratifying patients at risk of mortality during limited waiting time. We subsequently assessed the relationship between baseline variables, including patient-reported outcomes at registration of lung transplantation and waitlist mortality.

\section{Methods}

\section{Patients}

A total of 203 patients who were registered as candidates for lung transplantation from deceased donors were consecutively recruited from three facilities (Kyoto University Hospital, Okayama University Hospital, and Tohoku University Hospital) in Japan between March 2009 and
June 2015 [11]. The inclusion criteria were: (1) new registration in the Japan Organ Transplant Network; (2) age > 18 years; and (3) absence of uncontrolled comorbidities, such as malignant, cardiac, and cerebrovascular diseases. The exclusion criteria were: (1) necessity of heart-lung transplantation; and (2) refusal to participate in the study. Patients' background, pulmonary function, arterial blood gas, and patient-reported measurements of dyspnea, HRQL, and psychological status were assessed at study entry. Comorbidity was objectively assessed using the Charlson comorbidity index [12]. Patients underwent spirometry to measure their forced vital capacity (FVC) and forced expiratory volume in the first second $\left(\mathrm{FEV}_{1}\right)$. Predicted values were based on the recommendation by the Japanese Respiratory Society guidelines. The study protocol (E554) was approved by the Ethics Committees of all facilities participating in this research. Written informed consent was provided by all patients.

\section{Patient-reported outcomes}

Dyspnea was evaluated using the Japanese version of the modified Medical Research Council (mMRC) dyspnea scale $[8,9]$. This is a 5 -point scale $(0-4)$ based on the degrees of various physical activities that precipitate dyspnea; higher scores indicate a worse status.

Heath status or HRQL was assessed using the Japanese version of St. George's Respiratory Questionnaire (SGRQ) $[8,13]$. The SGRQ was originally developed for patients with chronic airflow limitations, such as asthma or COPD. However, it has been validated for use in other respiratory diseases, including pulmonary fibrosis, bronchiectasis, lymphangioleiomyomatosis, pulmonary hypertension, and bronchiolitis obliterans. Therefore, it is the only frequently employed respiratory-specific HRQL instrument in lung transplantation [14]. It consists of 50 items divided into three components: Symptoms, Activities, and Impacts. The Total SGRQ score was calculated, with scores ranging from 0 (best) to 100 (worst).

Psychological status was evaluated using the Japanese version of the Hospital Anxiety and Depression Scale (HADS) [11, 15], which consists of 14 items: seven for anxiety and seven for depression. Each item is scored from 0 to 3, where a score of 3 represents a state corresponding to the worst anxiety or depression. The sum of these items produces two subscale scores, each ranging from 0 to 21 .

\section{LAS}

The LAS of each patient was calculated using the LAS calculator on the Organ Procurement and Transplantation Network website (http://optn.transplant.hrsa. gov/resources/allocation-calculators/las-calculator/) in 
September 2020. In this study, the LAS was calculated using the data at the time of first study registration.

\section{Statistical analysis}

Results are presented as the median with interquartile range, unless otherwise stated. The duration from entry to the time of waitlist death (event), transplantation date including transplantations both from deceased and living donors (competing risk), or confirmation of survival without transplantation up to 5 years were recorded. Patients who withdrew from the study or remained on the waitlist were censored. We truncated the time-varying curves when $<10$ subjects were at risk.

Univariable and multivariable competing risk regressions with the Fine-Gray model [16] were performed to investigate the relationship between clinical measurements and waitlist mortality based on previous analyses $[7,8,17]$. FVC (\%predicted), interstitial lung disease (ILD), mMRC dyspnea, SGRQ, and HADS were included in the multivariable analyses based on clinical experience even if they were not significant variables in the univariable analyses. Other than these variables, those with $p$-values $<0.05$ were included in the multivariable analyses. Clinical measurements were defined as continuous variables with the exception of sex, smoking status, use of home oxygen therapy, and kinds of primary underlying diseases (ILD or other). The results of the regression analysis were presented as estimated hazard ratios (HRs) with corresponding 95\% confidence intervals (CIs). Competing risk regression with the Fine-Gray model was used to evaluate waitlist mortality in the groups with lower versus higher mMRC dyspnea, lower versus higher SGRQ score, and lower versus higher LAS based on the median score. The $p$-values $<0.05$ denoted statistically significant differences. Statistical analyses were performed using the statistical software EZR (Saitama Medical Center, Jichi Medical University, Saitama, Japan).

\section{Results}

\section{Patients}

Among the 203 patients enrolled, six patients were excluded (four were lost to follow-up and two were transferred to other hospitals immediately after registration). Therefore, 197 patients (102 males) who met the inclusion criteria were analyzed; their baseline characteristics are presented in Table 1 . The study population had a median age of $47(38-54)$ years and low body mass index of $19.0(16.7-21.7) \mathrm{kg} / \mathrm{m}^{2}$. The primary underlying diseases were ILD (99 patients, 50.3\%), bronchiolitis obliterans (21 patients, 10.7\%), pulmonary hypertension (15 patients, 7.6\%), lymphangioleiomyomatosis (15 patients, 7.6\%), COPD (12 patients, 6.1\%), bronchiectasis (11 patients, 5.6\%), and lung injury after hematopoietic stem
Table 1 Baseline characteristics of 197 patients waiting for lung transplantation

\begin{tabular}{|c|c|c|}
\hline Characteristics & Median or number & IQR \\
\hline Sex, male/female, $n$ & $102 / 95$ & \\
\hline Age, years & 47 & $38-54$ \\
\hline $\mathrm{BMI}, \mathrm{kg} / \mathrm{m}^{2}$ & 19.0 & $16.7-21.7$ \\
\hline Smokers, number & $94(47.7 \%)$ & \\
\hline Charlson comorbidity index & 0 & $0-1$ \\
\hline $\mathrm{PaO}_{2}, \mathrm{mmHg}$ & 74.5 & $62.0-88.9$ \\
\hline $\mathrm{PaCO}_{2}, \mathrm{mmHg}$ & 45.1 & $40.1-51.5$ \\
\hline FVC, L & 1.7 & $1.2-2.3$ \\
\hline FVC, \%predicted & 46.4 & $36.1-61.6$ \\
\hline $\mathrm{FEV}_{1}, \mathrm{~L}$ & 1.2 & $0.7-1.7$ \\
\hline $\mathrm{FEV}_{1}, \%$ predicted & 40.8 & $24.5-55.8$ \\
\hline 6-min walk distance, $\mathrm{m}$ & 300 & 208-389 \\
\hline mMRC dyspnea (0-4) & 3 & $2-4$ \\
\hline SGRQ symptoms (0-100) & 69.6 & $56.2-80.7$ \\
\hline SGRQ activities (0-100) & 86.4 & $77.2-92.5$ \\
\hline SGRQ impacts (0-100) & 57.5 & $43.3-70.1$ \\
\hline SGRQ total (0-100) & 67.3 & $56.5-76.7$ \\
\hline HADS anxiety (0-21) & 5 & $2-8$ \\
\hline HADS depression (0-21) & 6 & $3-9$ \\
\hline
\end{tabular}

Numbers in parentheses indicate the theoretical score range

There were some unavailable data: $\mathrm{PaO}_{2}$ and $\mathrm{PaCO}_{2}$ were measured in 195 patients, FVC and FEV ${ }_{1}$ were measured in 191 patients, and 6-min walk distance was measured in 179 patients

IQR interquartile range, $\mathrm{BMI}$ body mass index, $\mathrm{PaO}_{2}$ arterial partial pressure of oxygen, $\mathrm{PaCO}_{2}$ arterial partial pressure of carbon dioxide, $\mathrm{FVC}$ forced vital capacity, FEV ${ }_{1}$ forced expiratory volume in the first second, $m M R C$ modified Medical Research Council, SGRQ St. George's Respiratory Questionnaire, HADS Hospital Anxiety and Depression Scale

cell transplantation (10 patients, 5.1\%). Long-term oxygen therapy and noninvasive ventilation were used for 174 and 11 patients, respectively. FVC and $\mathrm{FEV}_{1}$ values were low at 46.4 (36.1-61.6) \%predicted and 40.8 (24.555.8) \%predicted, respectively.

\section{Prospective survival study}

During the median follow-up period of 572 days (range: 1-1987 days), 96 patients (48.7\%) received lung transplantation. Among them, 27 patients underwent livingdonor lung lobar transplantation because they could not wait for a deceased donor. Regarding the 69 patients who underwent lung transplantation from a deceased donor, the median time from registration to lung transplantation was 752 days (range: 38-1979 days). Of note, 72 patients on the waitlist (36.5\%) died: 49 had ILD, and 23 had other respiratory diseases. With regard to the cause of death, 70 patients (97.2\%) died due to worsening of the original respiratory diseases; the remaining two patients died due to pneumonia and pulmonary hemorrhage (one patient each). 
Univariable competing risk regressions with the FineGray model were performed to investigate the relationships between clinical measurements and waitlist mortality (Table 2). Higher age, ILD, higher arterial partial pressure of carbon dioxide $\left(\mathrm{PaCO}_{2}\right)$, and lower FVC were significantly related to waitlist mortality $(p<0.05)$. Regarding patient-reported measures, mMRC dyspnea was significantly related to waitlist mortality $(\mathrm{HR}=1.46$, 95\% CI 1.13-1.87, $p=0.003)$. For patients classified according to the median mMRC (3), cumulative incidence curves between the lower and higher mMRC score groups (score $0-2, \mathrm{n}=79$; score 3 or $4, \mathrm{n}=115$; missing, $\mathrm{n}=3$ ) are presented $(p=0.011)$ (Fig. 1). The HRQL, Symptoms, Activities, Impacts, and Total scores of the SGRQ were strongly associated with waitlist mortality $(\mathrm{HR}=1.02,95 \% \mathrm{CI} 1.01-1.04, p=0.0014 ; \mathrm{HR}=1.03,95 \%$ CI $1.01-1.05, p=0.002$; $\mathrm{HR}=1.03,95 \%$ CI $1.02-1.04$, $p<0.001$; and $\mathrm{HR}=1.04,95 \% \mathrm{CI} 1.02-1.05, p<0.001$, respectively). For patients classified according to the median SGRQ Total score (67.3), cumulative incidence curves between the higher and lower SGRQ Total score groups $(\mathrm{n}=97$ and $\mathrm{n}=98$, respectively; missing, $\mathrm{n}=2$ )

Table 2 Univariable competing risk analysis with the Fine-Gray model in 197 patients waiting for lung transplantation

\begin{tabular}{|c|c|c|c|}
\hline Characteristics & HR & $95 \% \mathrm{Cl}$ & $p$-value \\
\hline Sex, male & 1.08 & $0.68-1.71$ & 0.76 \\
\hline Age, years & 1.04 & $1.02-1.06$ & $<0.001$ \\
\hline $\mathrm{BMI}, \mathrm{kg} / \mathrm{m}^{2}$ & 1.00 & $0.94-1.05$ & 0.90 \\
\hline Smoking history & 1.01 & $0.64-1.62$ & 0.96 \\
\hline Charlson comorbidity index & 1.01 & $0.75-1.37$ & 0.96 \\
\hline Interstitial lung disease & 2.75 & $1.70-4.44$ & $<0.001$ \\
\hline Long-term oxygen therapy & 0.80 & $0.43-1.52$ & 0.50 \\
\hline $\mathrm{PaO}_{2}, \mathrm{mmHg}$ & 1.01 & $1.00-1.02$ & 0.14 \\
\hline $\mathrm{PaCO}_{2}, \mathrm{mmHg}$ & 1.02 & $1.00-1.04$ & 0.041 \\
\hline FVC, L & 0.58 & $0.43-0.80$ & $<0.001$ \\
\hline FVC, \%predicted & 0.98 & $0.97-0.99$ & $<0.001$ \\
\hline $\mathrm{FEV}_{1}, \mathrm{~L}$ & 0.92 & $0.68-1.25$ & 0.61 \\
\hline $\mathrm{FEV}_{1}, \%$ predicted & 1.00 & $0.99-1.01$ & 0.89 \\
\hline 6-min walk distance, $\mathrm{m}$ & 1.00 & $1.00-1.00$ & 0.55 \\
\hline mMRC dyspnea & 1.46 & $1.13-1.87$ & 0.003 \\
\hline SGRQ symptoms & 1.02 & $1.01-1.04$ & 0.0014 \\
\hline SGRQ activities & 1.03 & $1.01-1.05$ & 0.002 \\
\hline SGRQ impacts & 1.03 & $1.02-1.04$ & $<0.001$ \\
\hline SGRQ total & 1.04 & $1.02-1.05$ & $<0.001$ \\
\hline HADS anxiety & 1.07 & $1.02-1.13$ & 0.013 \\
\hline HADS depression & 1.05 & $1.01-1.10$ & 0.024 \\
\hline
\end{tabular}

$H R$ hazard ratio, $\mathrm{Cl}$ confidence interval, $\mathrm{BMI}$ body mass index, $\mathrm{PaO}_{2}$ arterial partial pressure of oxygen, $\mathrm{PaCO}_{2}$ arterial partial pressure of carbon dioxide, $\mathrm{FVC}$ forced vital capacity, FEV forced expiratory volume in the first second, $m M R C$ modified Medical Research Council, SGRQ St. George's Respiratory Questionnaire, HADS Hospital Anxiety and Depression Scale

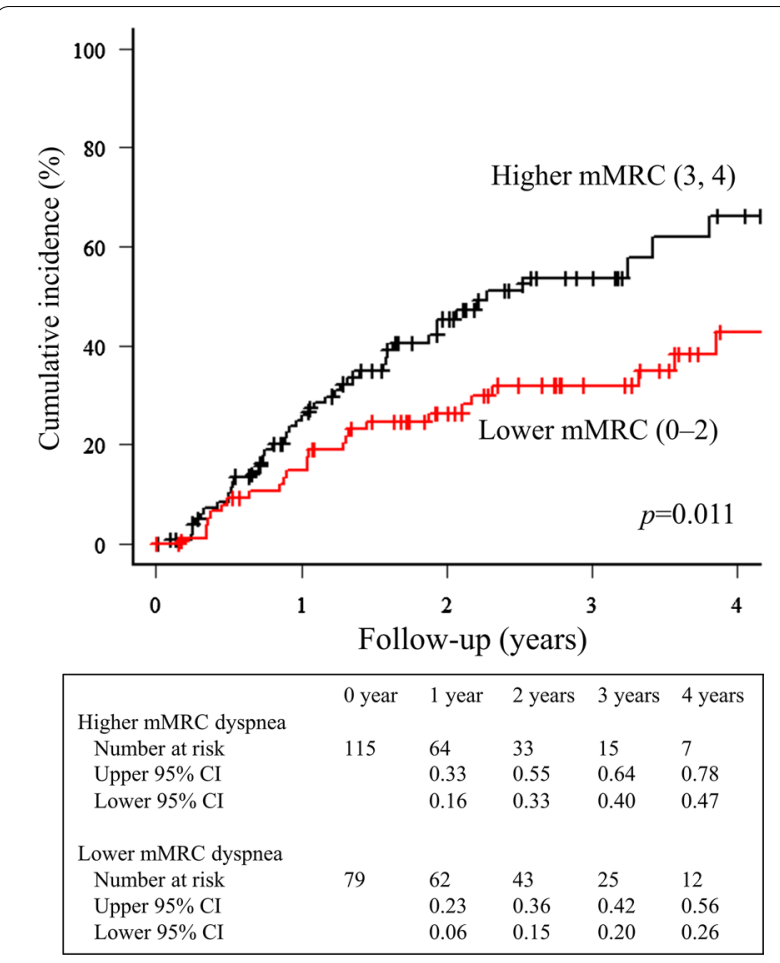

Fig. 1 Cumulative incidence on the waiting list comparing groups with higher and lower mMRC dyspnea based on the median score. The group with higher $\mathrm{mMRC}$ scores $(\mathrm{mMRC}=3$ or 4$)$ showed a significantly higher waitlist mortality rate than that with lower mMRC scores (mMRC $=0-2)(p=0.011)$. Cl confidence interval, $m M R C$ modified Medical Research Council

are presented $(p<0.001)$ (Fig. 2). HADS anxiety and depression were also weakly but significantly related to waitlist mortality $(\mathrm{HR}=1.07,95 \%$ CI $1.02-1.13$, $p=0.013$; and $\mathrm{HR}=1.05,95 \%$ CI $1.01-1.10, p=0.024$, respectively). Other variables, such as sex, body mass index, smoking history, comorbidities, long-term oxygen therapy, $\mathrm{FEV}_{1}$, and 6-min walk distance were not significantly related to waitlist mortality $(p>0.05)$.

Multivariable competing risk regression with the FineGray model was performed using age, ILD, $\mathrm{PaCO}_{2}$, FVC (\%predicted), and mMRC (Model I: dyspnea) or SGRQ Total score (Model II: HRQL) or HADS (Model III: psychological status) as explanatory variables; all were significant factors in the univariable analyses (Table 3). We divided them into these three groups because the SGRQ Total score includes the evaluation of dyspnea and psychological status. In Model I, age, ILD, FVC, and mMRC dyspnea were significantly related to waitlist mortality $(\mathrm{HR}=1.04, p=0.007 ; \mathrm{HR}=2.41, p=0.002 ; \mathrm{HR}=0.98$, $p=0.016 ;$ and $\mathrm{HR}=1.36, p=0.037$, respectively). In Model II, age, ILD, and SGRQ Total score were significantly related to waitlist mortality $(\mathrm{HR}=1.03, p=0.010$; $\mathrm{HR}=2.24, \quad p=0.003 ; \quad$ and $\mathrm{HR}=1.03, \quad p=0.0014$, 


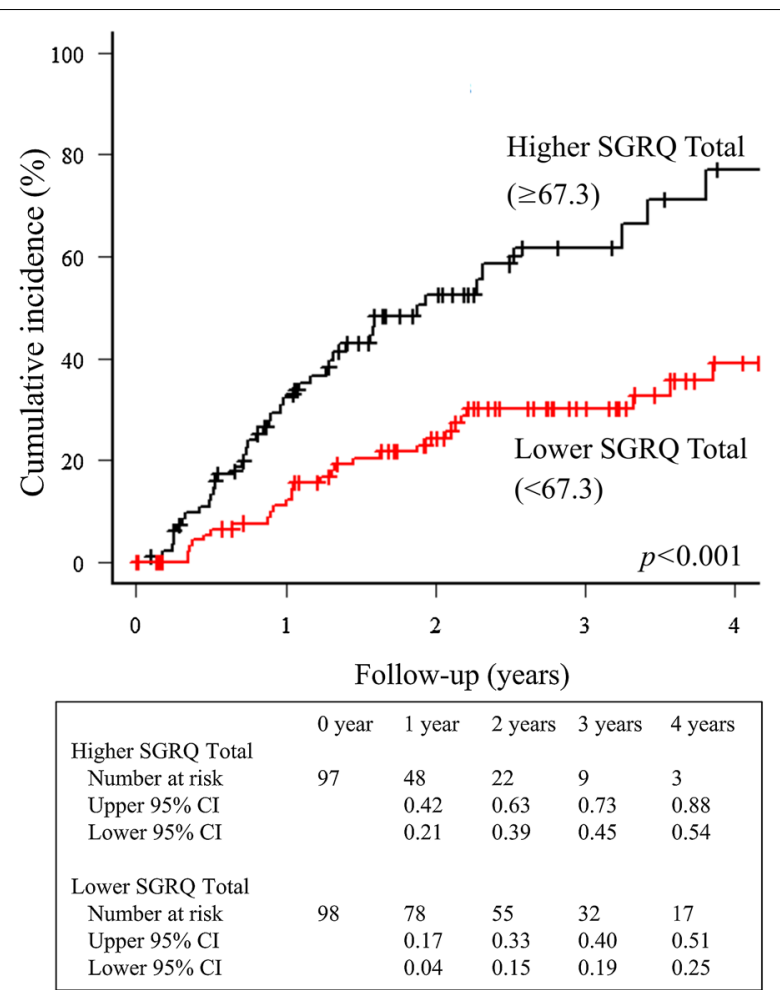

Fig. 2 Cumulative incidence on the waiting list comparing groups with higher and lower SGRQ Total score based on the median score. The group with higher SGRQ Total scores showed a significantly higher waitlist mortality rate than that with lower SGRQ Total scores $(p<0.001)$. Cl confidence interval, SGRQ St. George's Respiratory Questionnaire

respectively). In Model III, age, ILD and FVC were significantly related to waitlist mortality, whereas HADS was not. We also analyzed the data excluding patients who underwent living-donor lobar lung transplantation after registration in this study. We found that the SGRQ Total score and mMRC dyspnea remained significantly related to waitlist mortality after multivariable analysis (Additional file 1: Table S1).

Finally, we analyzed data regarding the LAS. The values ranged from 32.6 to 71.2 (median score: 40.1). Univariable competing risk analysis revealed that the LAS was significantly related to waitlist mortality $(\mathrm{HR}=1.04 ; 95 \%$ CI 1.01-1.07, $p=0.004)$. Cumulative incidence curves for the groups with lower versus higher LAS are presented $(\mathrm{n}=87$ and $\mathrm{n}=86$, respectively) $(p=0.025)$ (Additional file 2: Figure S1). We subsequently analyzed whether the significant relationship of the LAS with waitlist mortality was independent of patient-reported measures. Therefore, multivariable competing risk analysis was performed to investigate the relationships with waitlist mortality between the LAS and (a) Model I: mMRC score (dyspnea), (b) Model II: SGRQ Total (HRQL), and (c) Model III: HADS anxiety and depression (psychological status). In Model III, only the LAS was significant $(p=0.012)$; in Model I, both the LAS and the mMRC were significantly related to waitlist mortality $(p=0.039$ and 0.038 , respectively); and in Model II, the SGRQ was significantly related to waitlist mortality $(p<0.001)$, whereas the LAS was not $(p=0.11)$ (Additional file 3: Table S2).

\section{Discussion}

In the present study, we analyzed factors related to waitlist mortality in patients waiting for lung transplantation in Japan, focusing on patient-reported outcomes. The most important novel finding was that mMRC dyspnea and HRQL assessed using the SGRQ were significantly associated with waitlist mortality, in addition to other clinical variables such as age, underlying disease (ILD or non-ILD), and pulmonary function.

Table 3 Multivariable competing risk analysis with the Fine-Gray model to analyze the relationship between patient-reported outcomes and mortality in patients waiting for lung transplantation

\begin{tabular}{|c|c|c|c|c|c|c|c|c|c|}
\hline & \multicolumn{3}{|c|}{ Model I (dyspnea) } & \multicolumn{3}{|c|}{ Model II (HRQL) } & \multicolumn{3}{|c|}{ Model III (psychological status) } \\
\hline & HR & $95 \% \mathrm{Cl}$ & $p$-value & HR & $95 \% \mathrm{Cl}$ & $p$-value & $\mathrm{HR}$ & $95 \% \mathrm{Cl}$ & $p$-value \\
\hline Age, years & 1.04 & $1.01-1.06$ & 0.007 & 1.03 & $1.01-1.06$ & 0.010 & 1.04 & $1.01-1.06$ & 0.002 \\
\hline Interstitial lung disease & 2.41 & $1.38-4.21$ & 0.002 & 2.24 & $1.32-3.78$ & 0.003 & 2.10 & $1.26-3.51$ & 0.005 \\
\hline $\mathrm{PaCO}_{2}, \mathrm{mmHg}$ & 1.00 & $0.97-1.03$ & 0.950 & 1.00 & $0.97-1.04$ & 0.840 & 1.00 & $0.96-1.03$ & 0.830 \\
\hline FVC, \%predicted & 0.98 & $0.96-1.00$ & 0.016 & 0.99 & $0.97-1.01$ & 0.150 & 0.98 & $0.96-0.99$ & 0.002 \\
\hline mMRC dyspnea & 1.36 & $1.02-1.81$ & 0.037 & & & & & & \\
\hline SGRQ total & & & & 1.03 & $1.01-1.05$ & 0.0014 & & & \\
\hline HADS anxiety & & & & & & & 1.05 & $0.95-1.15$ & 0.330 \\
\hline HADS depression & & & & & & & 1.00 & $0.93-1.07$ & 0.970 \\
\hline
\end{tabular}

$H R Q L$ health-related quality of life, $H R$ hazard ratio, $C l$ confidence interval, $P a C O_{2}$ arterial partial pressure of carbon dioxide, $F V C$ forced vital capacity, $m M R C$ modified Medical Research Council, SGRQ St. George's Respiratory Questionnaire, HADS Hospital Anxiety and Depression Scale 
It is noteworthy that the patient-reported dyspnea and health were significantly associated with waitlist mortality in patients waiting for lung transplantation in the multivariable models. Some aspects of these sensory symptoms and experience can be objectively measured using questionnaires, enabling us to differentiate between patients with better or worse status (discriminative property) and assess their degree of change, e.g., in response to medical intervention (evaluative property) [18]. Subsequent studies reported that this approach can predict future outcomes, such as mortality in patients with COPD (predictive property) [7, 8]. Regarding idiopathic pulmonary fibrosis (IPF), the most prevalent original disease in the present study, mMRC dyspnea [19] and SGRQ $[20,21]$ also predicted mortality. Notably, well-established multi-dimensional severity scoring for IPF, such as the composite physiologic index [22] or GAP (gender, age and physiology) [23], did not include these measures.

However, we demonstrate for the first time that the predictive properties of both the mMRC and SGRQ score were advantageously maintained in this heterogeneous group of patients with various advanced lung disorders and targeted for lung transplantation. This information will help us to more accurately stratify patients at risk for waitlist mortality and better cope with this serious problem. These patients often have severe disease limiting their ability to perform important physiological tests, such as diffusing capacity or 6-min walk. Therefore, the use of appropriate questionnaires simplifies the assessment of dyspnea and HRQL in patients. Unlike pulmonary function, dyspnea and health can reflect systemic as well as local comprehensive effects of the disease on patients $[7,8]$.

Unfortunately, waitlist mortality remains a significant problem [1]. According to U.S. reports [1, 24], approximately $20 \%$ of waitlisted patients died while on the lung transplantation waitlist or are removed because they become ineligible for transplantation due to severe disease. Nevertheless, this mortality rate appears to be markedly lower than that observed in the present study (36.5\%). Long waiting time for lung transplantation is a serious problem in Japan and numerous other countries; hence, it is important to reduce waitlist mortality as much as possible.

Currently, there are nine certified lung transplantation centers in Japan, including Kyoto University. All potential recipients are evaluated by the nationwide Central Lung Transplant Evaluation Committee following acceptance by the Lung Transplant Evaluation Committee at each lung transplantation center [2]. Subsequently, the accepted candidates are registered on the waitlist of the Japan Organ Transplant Network Center. The selection of lung transplantation recipients in Japan is currently based on a "first come, first served" system, in addition to blood type compatibility, organ size, and other factors. The LAS system in the U.S. appears to function effectively. Numerous countries, including Japan, are attempting to develop such systems depending on their specific circumstances for lung transplantation. Given that the development of such systems may require considerable time, the present study was conducted to yield some scientific evidence with regard to risk stratification for organ allocation.

We calculated the LAS as a reference value, despite some missing values. Interestingly, the mMRC and SGRQ score were significantly related to mortality independently of the LAS. Thus, these subjective measures may add values to the existing lung allocation system in terms of patient risk stratification and patient perception. However, further prospective studies are warranted to examine this hypothesis.

ILD was significantly associated with waitlist mortality in different multivariable models. Among the 99 patients with ILD enrolled in this study, 49 patients (49.5\%) on the waitlist died. This is consistent with historical evidence [4] showing that patients with IPF have a higher waitlist mortality rate than those with other common indications for transplantation (67\% versus $18 \%$, respectively). In the U.S., the primary indications are fibrotic lung disorders, currently accounting for $>57 \%$ of cases [1]. Similarly, in the present Japanese study, ILD accounted for $50.3 \%$ of the 197 analyzed patients. Thus, ILD occupies a significant place in lung transplantation regarding incidence and waitlist mortality, which should be solved in the future.

Additionally, higher $\mathrm{PaCO}_{2}$ was an important factor for mortality. A previous retrospective study of patients with IPF in a single center yielded similar results [25]. The present prospective study corroborated these findings among heterogenous patients waiting for transplantation, not limited to IPF. In the future, we wish to investigate the potential usefulness of $\mathrm{PaCO}_{2}$ as a new biomarker for risk stratification.

Some limitations of the present study should be mentioned. Firstly, the present study was conducted in Japan where the LAS system is not used and the waitlist time is long. In Japan, allocation is solely based on the waiting time. In contrast, in the Eurotransplant region and the U.S., an allocation system is in place, stratifying patients based on medical urgency and anticipated 1-year survival. In addition, the underlying diseases of enrolled patients may differ between countries. Therefore, the present results may be specific to Japan. Moreover, because of the small number of patients, we were unable to perform an analysis based on each underlying disease. Our findings were only adjusted depending on the presence or absence of interstitial pneumonia through multivariable 
analysis. Hence, further study is warranted to determine the generalization of these findings. Secondly, we used mMRC and SGRQ score as measures of dyspnea and HRQL, respectively, both of which are well-established questionnaires in the respiratory field. However, as they are not specific to patients with severe diseases, the median and whole scores tended to skew toward worse outcomes. Lung transplant-specific instruments, such as the recent Lung Transplant Quality of Life (LT-QOL) [26], may generate better predictive features. Unfortunately, we did not have detailed data at the time of transplantation. This approach could provide insight into the association of mMRC and SGRQ score with the course of disease, in addition to mortality.

\section{Conclusions}

In this study, patient-reported dyspnea and health were significantly associated with waitlist mortality in patients waiting for lung transplantation, in addition to other clinical variables such as patients' age, underlying disease, and physiological measures. Patient-reported dyspnea and health may be measured through multi-dimensional analysis, including subjective perceptions. Following the development of a new allocation system in Japan, these parameters can be used for risk stratification regarding waitlist mortality.

\section{Supplementary Information}

The online version contains supplementary material available at https://doi. org/10.1186/s12931-021-01715-x.

Additional file 1: Table S1. Multivariable Fine-Gray proportional hazards analysis of the relationship between patient-reported outcomes and mortality in waitlisted patients, excluding those who underwent living-donor lung lobar transplantation after registration.

Additional file 2: Figure S1. Cumulative incidence on the waiting list comparing groups with higher and lower LAS scores based on the median score. $\mathrm{Cl}$, confidence interval; LAS, lung allocation score

Additional file 3: Table S2. Multivariable Fine-Gray proportional hazards analysis of the relationship of LAS and patient-reported outcomes with mortality in patients waiting for lung transplantation.

\section{Acknowledgement}

Not applicable.

\section{Authors' contributions}

$\mathrm{Ml}$ and TO had full access to all data analyzed in the study and take responsibility for the integrity of the data and the accuracy of the data analysis. MI, TO, TFC-Y, and HD contributed substantially to the study design, data analysis and interpretation, and the writing of the manuscript. All authors contributed to the acquisition of study data and drafting of the manuscript for important intellectual content. All authors read and approved the final manuscript.

\section{Funding}

This work was partly supported by a grant to the Respiratory Failure Research Group from the Ministry of Health, Labour and Welfare (no. 851160600002). The Department of Respiratory Care and Sleep Control Medicine, Kyoto University (KC) is funded by endowments from Philips-Respironics, Teijin Pharma,
Resmed Japan, Fukuda Denshi, and Fukuda Lifetec Keiji to Kyoto University (no. 201070700002).

\section{Availability of data and materials}

The datasets used and/or analyzed during the present study are available from the corresponding author upon reasonable request.

\section{Declarations}

Ethics approval and consent to participate

The study protocol (E554) was approved by the Ethics Committees of all facilities that participated in this research.

\section{Consent for publication}

Not applicable.

\section{Competing interests}

The authors have no competing interests to declare.

\section{Author details}

${ }^{1}$ Department of Thoracic Surgery, Graduate School of Medicine, Kyoto University, Kyoto, Japan. ${ }^{2}$ Department of Respiratory Medicine, Kawasaki Medical School, 577, Matsushima, Kurashiki, Okayama 701-0192, Japan. ${ }^{3}$ Department of Thoracic Surgery, Graduate School of Medicine, Nagoya University, Nagoya, Japan. ${ }^{4}$ Organ Transplant Center, Okayama University Hospital, Okayama, Japan. ${ }^{5}$ Department of Thoracic Surgery, Institute of Development, Aging and Cancer, Tohoku University, Sendai, Japan. ${ }^{6}$ Division of Organ Transplantation, Tohoku University Hospital, Sendai, Japan. ${ }^{7}$ Department of Respiratory Care and Sleep Control Medicine, Graduate School of Medicine, Kyoto University, Kyoto, Japan.

Received: 12 January 2021 Accepted: 13 April 2021

Published online: 21 April 2021

\section{References}

1. Ahya VN, Diamond JM. Lung transplantation. Med Clin N Am. 2019;103:425-33.

2. Date H. Current status and problems of lung transplantation in Japan. J Thorac Dis. 2016;8(Suppl 8):S631-6.

3. Egan TM, Murray S, Bustami RT, Shearon TH, McCullough KP, Edwards $L B$, et al. Development of the new lung allocation system in the United States. Am J Transplant. 2006;6:1212-27.

4. Smits JM, Nossent GD, de Vries E, Rahmel A, Meiser B, Strueber M, et al. Evaluation of the lung allocation score in highly urgent and urgent lung transplant candidates in Eurotransplant. J Heart Lung Transplant. 2011;30:22-8

5. George PM, Patterson CM, Reed AK, Thillai M. Lung transplantation for idiopathic pulmonary fibrosis. Lancet Respir Med. 2019;7:271-82.

6. Chen F, Oga T, Yamada T, Sato M, Aoyama A, Chin K, et al. Lung allocation score and health-related quality of life in Japanese candidates for lung transplantation. Interact Cardiovascular Thorac Surg. 2015;21:28-33.

7. Nishimura $K$, Izumi T, Tsukino M, Oga T. Dyspnea is a better predictor of 5 -year survival than airway obstruction in patients with COPD. Chest. 2002;121:1434-40.

8. Oga T, Nishimura K, Tsukino M, Sato S, Hajiro T. Analysis of the factors related to mortality in chronic obstructive pulmonary disease: role of exercise capacity and health status. Am J Respir Crit Care Med. 2003;167:544-9.

9. Global initiative for Chronic Obstructive Lung Disease. Global strategy for the diagnosis, management, and prevention of chronic obstructive pulmonary disease. (2021 report). https://goldcopd.org/2021-gold-repor ts/. Accessed 21 Dec 2020.

10. Celli BR, Cote CG, Marin JM, Casanova C, de Oca MM, Mendez RA, et al. The body-mass index, airflow obstruction, dyspnea, and exercise capacity index in chronic obstructive pulmonary disease. N Engl J Med. 2004;350:1005-12. 
11. Tokuno J, Chen-Yoshikawa TF, Oga T, Oto T, Okawa T, Okada Y, et al. Analysis of optimal health-related quality of life measures in patients waitlisted for lung transplantation. Can Respir J. 2020;2020:4912920.

12. Charlson ME, Pompei P, Ales KL, MacKenzie CR. A new method of classifying prognostic comorbidity in longitudinal studies: development and validation. J Chronic Dis. 1987;40:373-83.

13. Jones PW, Quirk FH, Baveystock CM, Littlejohns P. A self-complete measure of health status for chronic airflow limitation: the St. George's Respiratory Questionnaire. Am Rev Respir Dis. 1992;145:1321-7.

14. Singer J, Chen J, Blanc PD, Leard LE, Kukreja J, Chen H. A thematic analysis of quality of life in lung transplant: the existing evidence and implications for future directions. Am J Transplant. 2013;13:839-50.

15. Zigmond AS, Snaith RP. The hospital anxiety and depression scale. Acta Psychiatr Scand. 1983;67:361-70.

16. Fine JP, Gray RJ. A proportional hazards model for the subdistribution of a competing risk. J Am Stat Assoc. 1999;94:496-509.

17. Aihara K, Handa T, Oga T, Watanabe K, Tanizawa K, Ikezoe K, et al. Clinical relevance of plasma prostaglandin $\mathrm{F}_{2 a}$ metabolite concentrations in patients with idiopathic pulmonary fibrosis. PLOS ONE. 2013;8:e66017.

18. Oga T, Nishimura K, Tsukino M, Sato S, Hajiro T, Ikeda A, et al. Health status measured with the CRQ does not predict mortality in COPD. Eur Respir J. 2002;20:1147-51.

19. Nishiyama O, Taniguchi H, Kondoh Y, Kimura T, Kato K, Kataoka K, et al. A simple assessment of dyspnoea as a prognostic indicator in idiopathic pulmonary fibrosis. Eur Respir J. 2010;36:1067-72.

20. Case AH, Hellkamp AS, Neely ML, Bender S, Dilling DF, Gulati M, et al. Associations between patient-reported outcomes and death or lung transplant in idiopathic pulmonary fibrosis. Ann Am Thorac Soc. 2020;17(6):699-705.

21. Furukawa T, Taniguchi H, Ando M, Kondoh Y, Kataoka K, Nishiyama O, et al. The St. George's Respiratory Questionnaire as a prognostic factor in IPF. Respir Res. 2017;18:18.

22. Wells AU, Desai SR, Rubens MB, Goh NSL, Cramer D, Nicholson AG, et al. Idiopathic pulmonary fibrosis: a composite physiologic index derived from disease extent observed by computed tomography. Am J Respir Crit Care Med. 2003;167:962-9.

23. Ley B, Ryerson CJ, Vittinghoff E, Ryu JH, Tomassetti S, Lee JS, et al. A multidimensional index and staging system for idiopathic pulmonary fibrosis. Ann Intern Med. 2012;156:684-91.

24. Valapour M, Lehr CJ, Skeans MA, Smith JM, Uccellini K, Goff R, et al. OPTN/ SRTR 2018 annual data report: lung. Am J Transplant. 2020;20(Suppl s1):427-508.

25. Bennett D, Fossi A, Bargagli E, Refini RM, Pieroni M, Luzzi L, et al. Mortality on the waiting list for lung transplantation in patients with idiopathic pulmonary fibrosis: a single-centre experience. Lung. 2015;193:677-81.

26. Singer JP, Soong A, Chen J, Shrestha P, Zhuo H, Gao Y, et al. Development and preliminary validation of the Lung Transplant Quality of Life (LT-QoL) Survey. Am J Respir Crit Care Med. 2019;199:1008-19.

\section{Publisher's Note}

Springer Nature remains neutral with regard to jurisdictional claims in published maps and institutional affiliations.
Ready to submit your research? Choose BMC and benefit from:

- fast, convenient online submission

- thorough peer review by experienced researchers in your field

- rapid publication on acceptance

- support for research data, including large and complex data types

- gold Open Access which fosters wider collaboration and increased citations

- maximum visibility for your research: over 100M website views per year

At BMC, research is always in progress.

Learn more biomedcentral.com/submissions 